\title{
Planning deliveries from end to beginning: an assessment methodology proposal for big cities in developing countries, with real case application
}

\author{
D. Tacla ${ }^{1,3}$, O. F. Lima Jr ${ }^{1,3}$, S. Suyama ${ }^{2,3}$ \& R. C. Botter ${ }^{3}$ \\ ${ }^{1}$ Universidade Estadual de Campinas, LALT, Brazil \\ ${ }^{2}$ DHL Exel Supply Chain, Brazil \\ ${ }^{3}$ Escola Politécnica Universidade de São Paulo, \\ Naval Department, Brazil
}

\begin{abstract}
Delivering cargo in big cities in developing countries is more difficult than in developed countries, mainly because the infrastructure and traffic conditions are worse. Planning cargo distribution in urban areas is an issue anyway in all populous cities, but it is a critical problem in developing countries. The best technical option may be to use smaller and lighter vehicles in order to impact the traffic less, be more agile, save the environment using cleaner fuel, and also to make it easier to access central areas inside commercial centers. Cost, however, is a fundamental issue in this scenario; delivering cargo with a lot of small trucks can be much more expensive than full truck loads using bigger vehicles, big trucks ask for space and the terrain values and traffic conditions are not favorable for them. It may be important to find a solution to fit each case; but a customized solution slows productivity down and impedes standard policies for cities and the community; it will also be a problem for multinational companies. The proposal of this paper is to present a methodology to apply an assessment before choosing the mode of cargo delivery in the urban area of populous cities in developing countries, thinking from the end of the delivery chain to the beginning, also brings the application to a real case. The target is to create a process to choose between the conventional method, privileging the agility, short storage and small trucks (having the commercial issue as the main focus); or to use cargo consolidation, fewer stops, and larger trucks (having the logistic issue as the main focus).
\end{abstract}

Keywords: logistic, cargo transportation, urban delivery, traffic, planning. 


\section{Introduction}

Cargo transportation is each day becoming more complicated than before, even more urban cargo transportation. Globalization has meant an important increment in the quantity of goods moved, which means additional quantity above normal growth; products are much more volatile, people are forced by marketing actions to consume more, to change concepts, fashion is changing more quickly. More people, more consumers, more transportation and the same infra-structure; at least the infra-structure grows less and less quickly. In the third world, or developing countries, this situation is a huge problem, even more serious in big cities such as Sao Paulo in Brazil, for example.

Big cities in developed countries have the same kind of issue, but the globalization, marketing, or quick turnaround of fashion are not aggravated by economy growth or infra-structure investment shortage. Huge cities are as huge in Brazil as in Japan, Russia, India or the USA; but the impact is different, then the solution for cargo urban transportation must be different as well.

Today an issue that makes it more difficult to live in a big city is the transportation of cargo and people, put simply moving ourselves is expensive and takes a large part of our life. People and cargo compete for the same space on the streets, and they compete for the same space in the stores, competing also for time.

Urban cargo transportation has become more and more important because it directly impacts on the life of the people and the traffic in the central regions (e.g. Lima Jr. [6]). This issue reaches Third Part Logistics (3PL) with productivity; the common people that must live with the trucks and their noise and pollution. The governments of the majority of third world countries insist on trying to fix the situation with more laws and rules than infra-structure and planning; normally they only get more injuries to economy and business.

The urban cargo transportation in metropolitan areas can be analyzed through different focuses: 3PL, or carrier, impact by traffic, access difficulties and long lines to unload; cargo transportation users impacted by delivery delays and freight costs; and people themselves are also impacted by heavy traffic and pollution (noise and smoke). On the other hand urban cargo transportation is hugely important for the economy, both in respect of global and local business.

The players that are really involved in this game are, normally, the 3PL carrier and shippers; the ones that buy goods and/or receive them in their installations do not play. The objective of this paper is to create a scenario where the buyer, or cargo receiver, participates in the logistic planning and then works together with the carrier in order to build a better logistic solution. In this way the cargo transportation can be planning the in a customized way, from the end (receiver) to begin (shipper).

The proposal of this paper is to present a methodology to apply an assessment before to choosing the mode of cargo delivery in the urban area of populous cities in developing countries, thinking from the end of the delivery chain to the beginning. The target is to create a process to choose between the conventional method, privileging the agility, short storage and small trucks (having the 
commercial issue as the main focus); or to use cargo consolidation, fewer stops, and larger trucks (having the logistic issue as the main focus).

The methodology intends to support decision comparison and recommend the best delivery logistic plan; it also brings the application of a real case for global players that reach final customers with relevant aggregated value products.

The case studied in this paper and the database available offer a great opportunity for the development of a methodology capable of contributing to the framing of transportation planning considering the cargo receiver; as well to offer alternatives to mitigate urban cargo issues for practical implementation of the assessment, it also show a methodology applicable and the possibilities to help avoid additional troubles to the cities and save money, without losing focus on the environmental aspects.

\section{Problem characterization}

Transportation is the most expensive part of the logistic; it is a kind of consensus that $60 \%$ of the total logistic expenses come from transport. International transportation is relatively cheaper than domestic transportation; long distance dislocation is also relatively cheaper than urban delivery. Cargo delivery operations in mainly urban and central areas inside the commercial centre, are not only expensive, but are also a problem.

Consumer goods are urgent, so the customer does not wait for the product whose transportation cannot be paid for or is simply delayed. Globally the network must have an efficient local transportation solution. It is make no sense to have a lot of small trucks trying to access shopping centers at the same time; and competing with the car customers through over loaded streets; it also means more pollution. Usually, the goods seller does the logistic planning, which means:

1- The receiver (buyer or logistic final customer) asks for goods replacement based on his own forecast, inventory and available space;

2- The industry receives the order and starts the production forecast, asks for parts and raw material;

3- The industry dispatches the order to their 3PL, to their retailer, or directly to the receiver;

4- Goods are shipped to the receiver/store.

5- Thousands of small trucks are circulating right now inside towns, and some of them to the same stores with same kind of products.

The best technical option may be to use smaller and lighter vehicles in order to impact less on the traffic, be more agile, save the environment by using cleaner fuel, and to give easier access to central areas inside commercial centers. Cost, however, is a fundamental issue in this scenario; delivering cargo with many small trucks can be much more expensive than full truck loads using larger vehicles. Deliveries with big trucks need space and the terrain values and traffic conditions are not favorable for them. It may be important to find a solution to fit each case; but a customized solution lowers productivity and impedes standard 
policies for cities and community; as well as being a problem for multinational companies.

There is no definitive right option between making deliveries through small or big trucks; the answer depends on the situation and focus.

If the planning starts in the usual way: from the shipper to the receiver, it is natural that the shipper makes all efforts to attend the customer's expectation concerning locating the right goods at the moment desired by this customer; in order to attend service level agreements the logistic chosen cannot be the best possibility, it can mean more trucks, more pollution and traffic. On the other hand, the customer perhaps would not be satisfied if the shipper tries to optimize the logistic operation using fewer trucks, saving money and/or the environment.

Planning from the end, starting with the final customer, is to think of the global necessity to attend a set of criteria; for example to determine when to replace the inventory of a sales sector (such as informatics or sportswear, etc). This way, the receiver will plan the logistic and the logistic process can be optimized without commercial damage; it can be a very good solution for big retailers, department stores, shopping centers, etc.

Nevertheless it is not always possible to plan from the final customer's view for a set of invoices; maybe because the customer is not big enough, or does not have a wide enough variety of products to allow this kind of planning, or for any other reason.

The challenge is to find a set of criteria to permit one to decide which process is better. This paper presents a methodology to make an assessment to help to support the decision.

\section{Study proposal: assessment methodology to plan deliveries from the end to the beginning}

The focal point of this methodology is the fleet assignment; after determining the delivery planning and service level characterization in terms of shipment and receiving, the final proposed product of this paper will impact on the fleet to be assigned.

If the focal point is fleet assignment, the key is consolidation. In a few words: the point is to design cargo consolidation in between two alternatives:

1. Consolidation pointing to regional delivery - planning from start (shipper) to end (receiver);

2. Consolidation pointing to final receiver - planning from end (receiver) to beginning (shipper).

The methodology proposed can be summarized as follows, but better understanding will come with real case application:

A fleet of different types of vehicles is available to be assigned to routes, each one has a given capacity, and each transportation request has the cargo amount to be loaded, the origin point and locations where it is to be delivered. Starting from a set of orders, the correspondent set of points has to be checked in order to satisfy transportation requests; those requisitions can be obtained by applying the 
assessment. The main part of the methodology proposed is the assessment presented in figure 1 .

This assessment application provides a score that indicates the possibility of the delivery logistic being direct and exclusive, or making consolidated transportation to the customers' (more than one) region. The score will be determined to track the support decision about logistic planning. The planning requires much more than this step, but the score assessment will support the decision before planning begins. In order to be able to deal with all these various complicating characteristics, which are for the most part dependent upon the final customers, and keep the logistics focus, planning has to be reformulated. The objective is to consolidate cargo at the origin point, creating two kinds of loads: first one privileging the agility, short storage, small trucks and another one with the logistic issue regarding fewer stops and larger vehicles. This methodology does not provide the planning, but is a good indication to support the decision between the two options. In a very simple way, figure 2 illustrates where planning has to be done from the end and who is responsible for what.

The concepts to support this propose are:

- $\quad$ Fewer transportation costs, reducing the number of vehicles required;

- $\quad$ Reducing the number of vehicles at each point of destination;

- $\quad$ Routing truck deliveries;

- Saving the environmental system.

\section{Real case implementation of proposed methodology}

The case comes from a real application of the DHL Exel Supply Chain in Sao Paulo, Brazil and the database was collected in the automotive sector. The

\begin{tabular}{|c|c|c|c|}
\hline Are final customers located outside Central Area? & Yes & No & \\
\hline Are small vehicles necessary? & Yes & No & \\
\hline Is there compatibleness to others cargo? & Yes & No & \\
\hline Is there a time window discharge agreed with final customer? & Yes & No & \\
\hline How are frequencies of orders? & \begin{tabular}{|l|} 
Less than \\
once a \\
week
\end{tabular} & $\begin{array}{l}\text { Once or } \\
\text { twice }\end{array}$ & $\begin{array}{l}\text { More than } \\
\text { two }\end{array}$ \\
\hline What is the relation between cargo value and cubic weight? & \begin{tabular}{|l|} 
Less than \\
$\mathrm{R} \$ 50$
\end{tabular} & \begin{tabular}{|l|}
$R \$ 50$ to \\
$R \$ 100$
\end{tabular} & $\begin{array}{l}\text { More than } \\
\mathrm{R} \$ 100\end{array}$ \\
\hline Constraints of vehicle type nearby final destination? & Yes & No & \\
\hline Is there a waiting park at final destination? & Yes & No & \\
\hline Does final customer receive orders parcially? & Yes & No & \\
\hline
\end{tabular}

Figure 1: $\quad$ Assessment for delivery mode. 


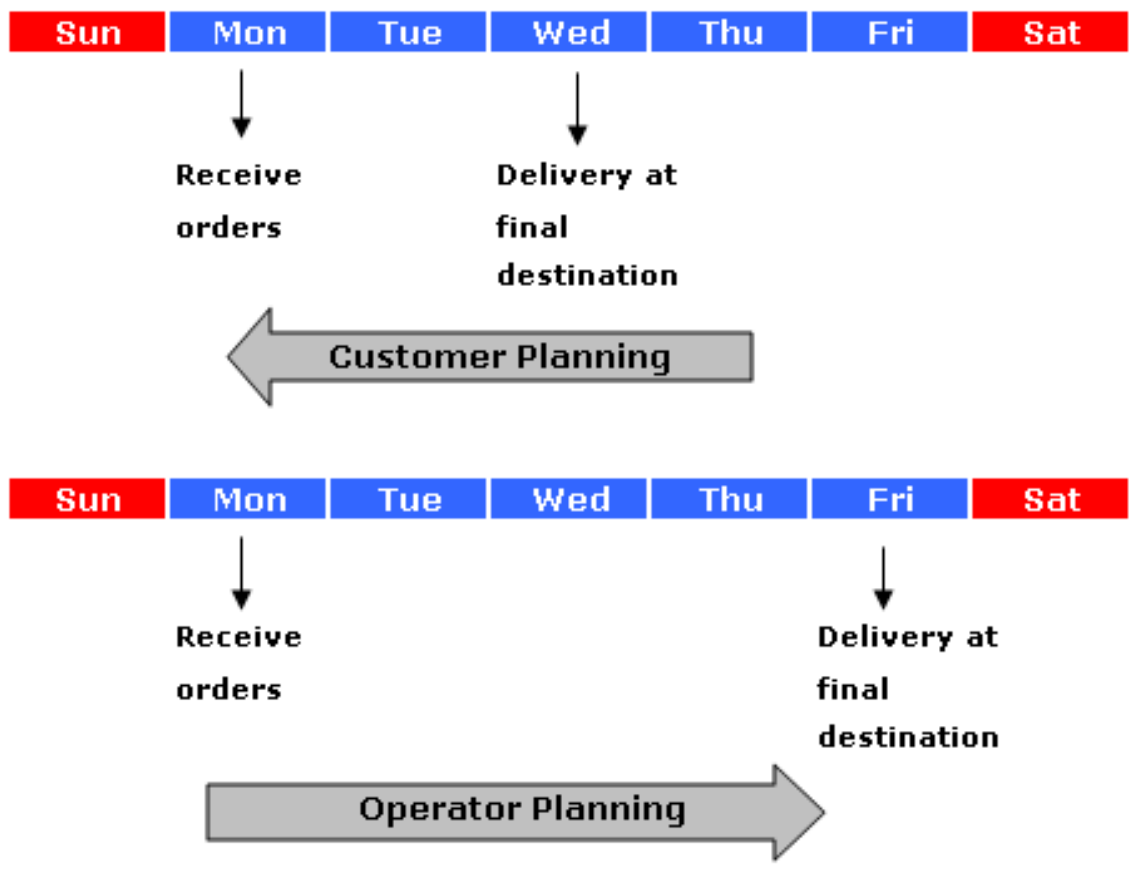

Figure 2: Principles of planning.

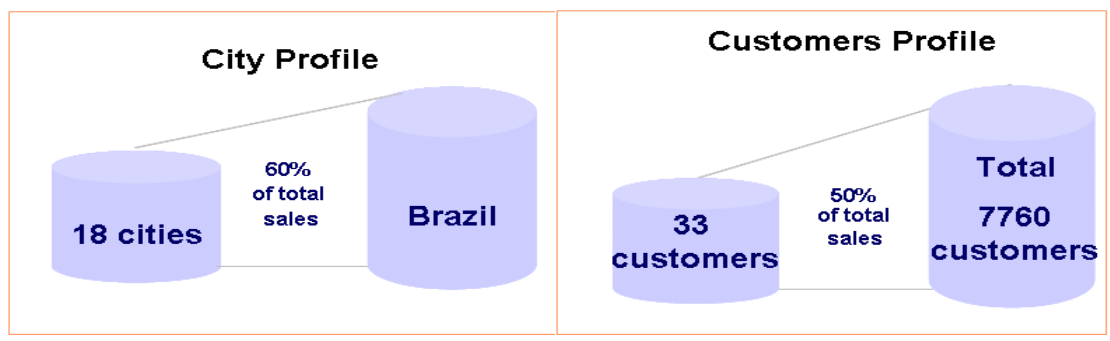

Figure 3: $\quad$ City and customers profile.

decision point is to choose to plan the cargo from the DHL Distribution Centre consolidating the cargo delivery to several different customers in the same region, or to consolidate all primary shippers to the same final customers, in this case an automotive retailer that works with different automotive parts. In order to try to characterize the case study, a representation is presented in figure 3; from this figure it is possible to see that 33 customers, named customer " $\mathrm{A}$ ", are responsible for $50 \%$ of total sales and 18 cities are responsible for $60 \%$ of total sales.

Customer "A" was selected due to their shipment volume concentrate. 


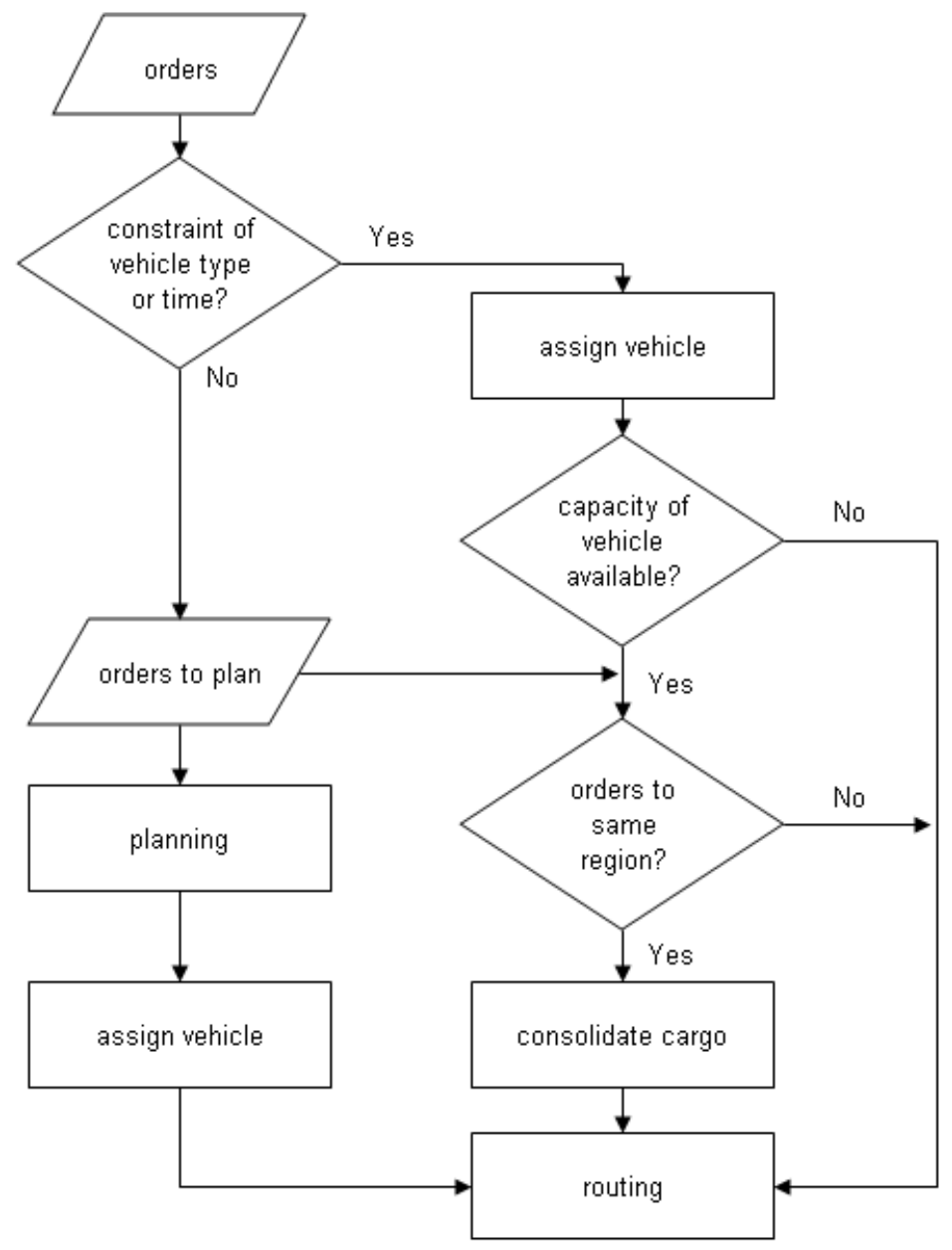

Figure 4: Conceptual flow.

Figure 4 presents the conceptual flow that illustrates the process of planning that supports the assessment in order to decide whether to plan from the end to the beginning or not.

As proposed in this study, the assessment was applied to these " $\mathrm{A}$ " customers and the resulting score was 33 , it means that possibly $33 \%$ of deliveries are going to be direct or exclusive, so the best logistic is to consolidate (see figure 5). Some of the customers present a high frequency of orders, which can be explained by lack of space to store cargo at stores, the area and inventory are too expensive. They are great drivers to start planning deliveries taking into account vehicle availability, because once the vehicle is assigned to them it is for certain that all constrains were submitted. Another advantage of planning from the end 
to the beginning is to gain transit time, about one day on short distance routes and three days on long distances. The saving on freight can reach $29 \%$.

The time between orders and deliveries becomes smaller and the customer service level becomes higher, on the other hand, for some final customers, there are so many restrictions that it seems to be the drivers for other customers who are carrying out the cargo planning.

\begin{tabular}{|c|c|c|}
\hline $\begin{array}{l}\text { Are final customers located outside Central } \\
\text { Area? }\end{array}$ & Yes & No \\
\hline Are small vehicles necessary? & Yes & No \\
\hline Is there compatibleness to others cargo? & Yes & No \\
\hline $\begin{array}{l}\text { Is there a time window discharge agreed } \\
\text { with final customer? }\end{array}$ & Yes & No \\
\hline How are frequencies of orders? & $\begin{array}{l}\text { Less than } \\
\text { once a } \\
\text { week }\end{array}$ & $\begin{array}{l}\text { Once or } \\
\text { twice }\end{array}$ \\
\hline $\begin{array}{l}\text { What is the relation between cargo value } \\
\text { and cubic weight? }\end{array}$ & $\begin{array}{l}\text { Less than } \\
R \$ 50\end{array}$ & $\begin{array}{l}R \$ 50 \text { to } \\
R \$ 100\end{array}$ \\
\hline $\begin{array}{l}\text { Constraints of vehicle type nearby final } \\
\text { destination? }\end{array}$ & Yes & No \\
\hline Is there a waiting park at final destination? & Yes & No \\
\hline $\begin{array}{l}\text { Does final customer receive orders } \\
\text { parcially? }\end{array}$ & Yes & No \\
\hline
\end{tabular}

\section{Best delivery logistic plan -> Consolidate}

Figure 5: Customer "A" assessment.

\section{Conclusions}

The study reached the target. First of all, the assessments were applied to two very different customers and the results were satisfied, one with the best logistic delivery plan of consolidating and the other one being direct/exclusive (figure 6); then the assessment was applied to customer " $\mathrm{A}$ " from the automotive sector and the "new" ways of delivery were tested.

The planning project determinates time window discharge restrictions and traffic conditions more rigidly than before, orders have to be made as early as possible; in fact the planning must be started in the warehousing picking phase. 
The benefits, on the other hand, are relevant and can be summarized as followed, part of the results are not directly measurable, but perceptible:

- Value aggregated at deliveries, closeness to final customers and partnership. The final customers were much more satisfied with the logistic provider.

- $\quad$ For the primary customers (the shippers) the costs did not increase and they were more satisfied with the satisfaction of their customers.

- Transit time would be reduced by about 30\% compared to previous transit time (original planning), mainly because of the consolidation at origin.

- Trucks and drivers are dedicated (or partially dedicated) to the operation, so it means trucks are optimized and drivers trained.

- Urban constrains can be attended with specific actions without causing problems to the logistic or commercial damage, because the planning is specific for this operation conciliates this constrain with the planning

- The transportation cost was reduced by $29 \%$, and this saving was shared between the players.

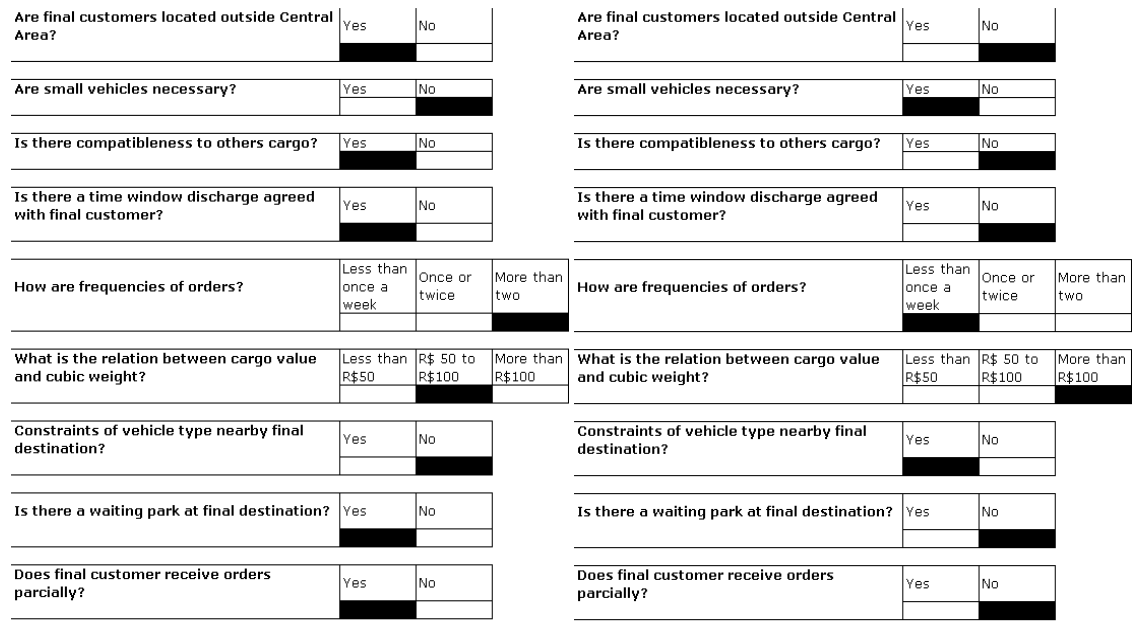

Best delivery logistic plan -> Consolidate

Best delivery logistic plan -> Direct/exclusive

Figure 6: Comparative consolidate and direct/exclusive.

The methodology works, and the benefits of planning from the end to the beginning are very important with regard to costs, service, and urban constraints attendance.

It is necessary, however, before applying this concept, to find out if it is feasible or not, and this methodology paper proposal intends to support this decision.

If this proposal utilization shows a positive score for planning the delivery of urban cargo transportation from the end to the beginning, this concept is strongly 
recommended, since the benefits in terms of costs, service and traffic are very important for the logistic system and the society.

\section{References}

[1] Bowersox D. J., Closs D. J. Logistical Management: The Integrated Supply Process. McGraw-Hill. USA, 1996.

[2] Browning, B. White, A. Collaborative Transportation Management - A Proposal, USA, 2001.

[3] Desrochers, J. Soumis, F; Belanger, N; Ioachim. Fleet Assignment and Routing With Schedule Synchronization Constraints. I. European Journal of Operation Research 119 (Elsevier Science), 1999.

[4] Gorham, Roger. Air pollution from ground transportation: an assessment of causes, strategies and tactics, and proposed actions for the international community. Department of Economic and Social Affairs, United Nations, 2002.

[5] Lamming, R., et al. An initial classification of supply networks. International Journal of Operations \& Production Management. V. 20, n.6, p. 675-691, EUA, 2000.

[6] Lima Jr., O. F. A Carga na Cidade: Hoje e Amanhã, LALT Universidade Estadual de Campinas, 2005.

[7] Tacla, D. Lima Jr. O. F., Botter, R.C. A Collaborative Transportation Proposal For Urban Deliveries: Costs And Environmental Savings, White paper, 2006.

[8] Tacla, D. Lima Jr., O. F., Botter, R.C. Suyama S. Planning a Good Logistic Net Working Design Can Save Money and Environmental for Urban Cargo Deliveries. White paper, 2007. 